\title{
A 3 GHz PHOTOELECTRON GUN FOR HIGH BEAM INTENSITY
}

\author{
R. Bossart ${ }^{*}$, H. Braun, M. Dehler, J.-C. Godot \\ European Organization for Nuclear Research (CERN), \\ CH-1211 Geneva 23, Switzerland
}

\begin{abstract}
For the Compact Linear Collider Test Facility (CTF) at CERN a new rf gun with a laser driven photocathode is under construction. The new rf gun will replace the present $1^{1 / 2}$ cell gun and will consist of $2^{1 / 2}$ cells accelerating the beam to a momentum of $7.0 \mathrm{MeV} / \mathrm{c}$ with an electric field strength of $100 \mathrm{MV} / \mathrm{m}$. The strong space-charge forces at low beam energy caused by the high charge density of the electron bunches are contained by radial and longitudinal rf focusing in the gun. The rf gun under construction has been optimized by MAFIA beam simulations for an injector assembly comprising a second accelerating if structure and an intermediate solenoid magnet correcting the beam divergence of the $2^{1 / 2}$ cell gun. The beam loading of the rf gun, by a train of 48 bunches with $21 \mathrm{nC}$ charge each, causes a strong energy decay accompanied by an increase of the flight time for the bunches with lower energy. These effects can be corrected by slightly shifting the acceleration frequency of the gun. The experimental results obtained with the $1^{1 / 2}$ cell gun and booster section presently in operation are reported.
\end{abstract}

Presented at the 17th International Free Electron Laser Conference, August 21-25 1995, New York, USA

* Corresponding Author FAX ++4122-767-8590 


\section{INTRODUCTION}

At the Compact Linear Collider Test Facility (CTF) at CERN, an rf photoelectron gun with $1 \frac{1 / 2}{2}$ cells of the Brookhaven type [1] has been in operation since 1990. It has been complemented by a second rf section of 4 cells in order to boost the beam momentum from 4.5 MeV/c at the gun exit to $11 \mathrm{MeV} / \mathrm{c}$ for better injection into the subsequent TW section of CTF. Both the rf gun and the booster section are standing wave structures excited in the ${ }^{1}$-mode at a frequency of $2998.5 \mathrm{MHz}$, with an electric field strength of up to $120 \mathrm{MV} / \mathrm{m}$ in the rf gun and $70 \mathrm{MV} / \mathrm{m}$ in the booster section [2]. The SW sections are pulsed during $2 \mu \mathrm{s}$ at a pulse rate of $10 \mathrm{~Hz}$. For higher beam intensity, the new gun with $2^{1 / 2}$ cells will be installed for the drive beam in place of the $1^{1 / 2}$ cell gun, see fig. 1 .

The new $3 \mathrm{GHz}$ photoelectron gun will produce a bunch train of 48 ultrashort electron bunches of $21 \mathrm{nC}$ charge each with a bunch length of $8 \mathrm{ps}$ fwhm or shorter. Radial rf focusing is achieved by a conical backplane around the photocathode in the first cell where the electrons have a low energy. Longitudinal rf focusing is obtained by shortening the length of the following cells. The total electric charge of the bunch train is $1 \mu \mathrm{C}$ absorbing half of the rf energy stored in the cells.

The charge per bunch is limited mainly by space-charge forces in the rf gun and by transverse wakefield forces in the rf acceleration sections. Since the duration of the bunch train is much shorter than the filling time of the rf structures, the total charge of the bunch train is limited by the beam loading of the rf sections. An upper limit of total charge produced is attained when the drive beam has used up about half of the rf energy stored in the rf gun.

For good efficiency of $30 \mathrm{GHz}$ power extraction from the drive beam, the electron bunches have to be shorter than $2 \mathrm{~mm}$ fwhm, and the longitudinal positioning of the electron bunches should not deviate by more than $\pm 1 \mathrm{~mm}$ from the ideal bunch position at multiples of the rf wavelength. At present, the shortest bunch length measured with a streak camera at the exit of the booster section amounts to $2.1 \mathrm{~mm}$ fwhm. Beam tests at CTF are underway to reduce this bunch length by a magnetic bunch compressor at a beam momentum of $11 \mathrm{MeV} / \mathrm{c}$. For magnetic bunch compression all bunches of the bunch train must have the same momentum, otherwise the bunch spacing in the train is modified.

\section{PERFORMANCE OF THE GUN WITH 11/2 CELLS AND THE 4 CELL BOOSTER}

The modular electron gun consisting of the $1 \frac{1}{2} 2$ cell gun, the 4 cell booster and an intermediate focusing solenoid has been in operation since April 1994. The two rf sections have been conditioned rapidly to their nominal electric field strength of $100 \mathrm{MV} / \mathrm{m}$ for the gun and $65 \mathrm{MV} / \mathrm{m}$ for the booster section, powered each by $6 \mathrm{MW}$ of rf pulse power from the 
same $3 \mathrm{GHz}$ klystron. The $1 \frac{1 / 2}{1}$ cell gun together with the booster section and the intermediate solenoid magnet have produced an electron bunch train of 48 bunches with a momentum of $9.5 \mathrm{MeV} / \mathrm{c}$ and a total electric charge of $450 \mathrm{nC}$. The maximum electron charge produced in a single bunch was $35 \mathrm{nC}$ with a bunch length of $16 \mathrm{ps}$ fwhm at the exit of the booster section.

After 300 hours of rf operation, the quantum efficiency of the photocathode is typically $2 \%$ for an electric field strength of $110 \mathrm{MV} / \mathrm{m}$ peak. The electron yield of the photocathode and $\mathrm{rf}$ gun has been measured for different accelerating fields $50 \mathrm{MV} / \mathrm{m}^{2} \mathrm{E}^{2} 120 \mathrm{MV} / \mathrm{m}$. It has been verified that the quantum efficiency grows linearly with the $3 \mathrm{GHz}$ electric field strength $\mathrm{E}$ of the $\mathrm{Cs}_{2} \mathrm{Te}$ photocathode. There is very little beam loading by dark current in the $\mathrm{rf}$ gun at $100 \mathrm{MV} / \mathrm{m}$. At $124 \mathrm{MV} / \mathrm{m}$ the dark current reduces the accelerating rf field in the gun by $5 \%$.

The high beam charge produced by the gun causes a heavy energy droop Æ $\gamma$ between the beginning and end of the bunch train. The energy droop along the bunch train causes a reduction of beam velocity, $\Delta \beta$, which is most pronounced at low beam energy $\gamma$. In the drift space of length 1 at the exit of the gun, the bunch train is elongated by $\Delta \mathrm{z}=1 \Delta \beta / \beta \cong 1(\Delta \gamma / \gamma) /\left(\gamma^{2}-1\right)$.

Most important is the increase of flight time in the rf gun itself, where the beam is accelerated from zero to relativistic velocity. Since the high intensity beam of $450 \mathrm{nC}$ reduces the stored rf energy of the gun by half, the beam velocity slows down as the peak field strength declines from $100 \mathrm{MV} / \mathrm{m}$ for the first bunch to $70 \mathrm{MV} / \mathrm{m}$ for the last bunch. According to MAFIA beam simulations [3], the elongation of the bunch train amounts to $\Delta \mathrm{z}_{1}=3 \mathrm{~mm}$ in the $1^{1 / 2}$ cell gun of CTF.

\section{DESIGN OF RF GUN WITH 21/2 CELLS FOR HEAVY BEAM LOADING}

The successful design of the S-band rf gun by BNL Brookhaven [1] has found users in many laboratories. The aperture coupling between cells by a thick iris provides about equal peak field strength on the cavity surface $\left(\mathrm{E}_{\mathrm{pk}}\right)$ and on the beam axis $\left(\mathrm{E}_{\mathrm{Z}}\right)$, so that a high accelerating field strength $E_{Z}>100 \mathrm{MV} / \mathrm{m}$ at $3 \mathrm{GHz}$ is combined with a relatively low dark current caused by field emission from the copper surfaces.

The BNL gun is capable of producing high-intensity bunches of $35 \mathrm{nC}$ if the diameter of the photocathode and laser spot are enlarged. However, at higher charge the bunch length becomes excessively long due to strong space-charge forces. By increasing the iris aperture, the bunch radius can be increased and thereby the space-charge forces are reduced. In order 
to produce a higher bunch charge in the gun and to reduce the beam loading factor $\mathrm{k}_{0}^{\prime}$ of the cavity, the iris diameter for the new gun has been increased to $40 \mathrm{~mm}$.

The $2^{1 / 2}$ cell gun will be powered by $17 \mathrm{MW}$ during $2 \mu$ s providing a beam momentum of $7.0 \mathrm{MeV} / \mathrm{c}$ for a field strength of $100 \mathrm{MV} / \mathrm{m}$ in all cells. The number of cells has been restricted to $2 \frac{1}{2}$ because of the limited rf power available. The shape of the cell is spherical, as for the booster section, providing a higher Q-value. The rf parameters of a spherical full cell are listed in table 1.

The transverse focusing forces in the first half cell are caused by a conical backplane around the photocathode. Transverse rf forces in the region of the photocathode counteract the radial space-charge forces of the relativistic electron bunch. The optimum cone angle depends on the bunch charge and shape. Additional radial rf focusing is obtained by elongating the first half cell from 25 to $33 \mathrm{~mm}$. Longitudinally, by shortening the length of the second and third cell from 50 to $46 \mathrm{~mm}$, the energy dispersion $\Delta \gamma / \gamma$ caused by spacecharge forces is reduced.

The shunt impedance $\mathrm{R}_{\text {eff }}^{\prime}$ and the beam loading factor $\mathrm{k}_{0}^{\prime}=\pi f \mathrm{R}_{\text {eff }}^{\prime} / \mathrm{Q}_{0}$ are smaller for a larger iris diameter. As the iris diameter is enlarged, the coupling factor $\mathrm{k}_{12}$ between cells grows rapidly. Due to the stronger coupling between cells, rf energy is exchanged faster and the first half cell can be powered through the iris aperture from the second cell. For a larger iris diameter the passbands of the hybrid dipole modes HEM 11 come closer to the accelerating frequency. At equal phase velocity with the beam, these dipole modes deflect the beam transversely. Since the rf gun has only a few cells which all have different dipole frequencies, the risk of beam break-up is small.

Most important for the transverse beam emittance and beam divergence at the gun exit is the beam dynamics in the first half cell. The electric field strength on the photocathode must be as high as possible, $\mathrm{E}_{\mathrm{c}}=100$ to $130 \mathrm{MV} / \mathrm{m}$, in order to accelerate the high charge electron bunches to the highest possible energy, $\gamma>4$. With a high accelerating field gradient, the effects of the space-charge forces are minimized. The evolution of the beam radius from the photocathode, $\mathrm{PC}$, to the gun exit is shown in fig. 2. The beam characteristics of the $2 \frac{1}{2} 2$ cell gun are summarized in table 2 .

\section{COMPENSATION OF BEAM LOADING}

In the next test series CTF-2, the two beam acceleration scheme will be tested with a drive beam and a pilot beam. The drive beam of CTF-2 will be composed of 48 bunches spaced at $100 \mathrm{~mm}$ rf wavelength, with an electric charge of $21 \mathrm{nC}$ per bunch and a bunch length shorter than $2 \mathrm{~mm}$ fwhm. A relatively low charge per bunch has been chosen to 
alleviate the head-tail effects of single bunches. The total charge of the bunch train is considerable, $\mathrm{q}=48 \times 21 \mathrm{nC}=1 \mu \mathrm{C}$, and absorbs roughly half of the rf energy stored in the $2^{1 / 2}$ cell gun. According to beam simulations, the $2 \frac{1}{2}$ cell gun accelerates the first bunch to an energy of $7.0 \mathrm{MeV}$, but the last bunch to $5.0 \mathrm{MeV}$ only since the initial accelerating field strength of $100 \mathrm{MV} / \mathrm{m}$ is reduced to $70 \mathrm{MV} / \mathrm{m}$ by the beam loading. The beam loading factor $\mathrm{k}_{0}$ obtained from beam simulations amounts to $\mathrm{k}_{0}=\Delta \mathrm{U} / 2 \mathrm{q}=1000 \mathrm{~V} / \mathrm{nC}$ for $\Delta \mathrm{U}=2.0 \mathrm{MV}$. The beam loading factor $\mathrm{k}_{0}=\pi \mathrm{f} R / \mathrm{Q}$ calculated from the $\mathrm{rf}$ parameters of the gun is somewhat higher because it neglects the low beam velocity in the first half cell.

The decay of acceleration voltage $\Delta \mathrm{U}$ during the bunch train causes a large energy decrease, see fig. 3 , and hence reduces the beam velocity in the gun. The propagation time of the electron bunches increases by 8 ps from the first to the last bunch at the exit of the gun, fig. 4 . The increase of flight time in the gun causes a frequency offset of the bunch train by $0.5 \cdot 10^{-3}$ or $1.5 \mathrm{MHz}$.

A simple way to reduce the dispersion effects of the beam loading in the rf gun is to increase the stored rf energy by $50 \%$ so that the first bunch is accelerated by a field strength of $125 \mathrm{MV} / \mathrm{m}$ and the last bunch by $98 \mathrm{MV} / \mathrm{m}$. Thereby the increase of the flight time is only $4 \mathrm{ps}$ for a bunch train of $1 \mu \mathrm{C}$ total charge, and the beam energy is raised to $17.2>\gamma>13.5$.

The flight time of the individual bunches in the gun can be stabilised if the rf phase between the gun and the laser pulse is gradually shifted, so that the accelerating field $\mathrm{E}_{\mathrm{c}}$ on the photocathode increases slightly during the pulse train. The exact phase of the last bunch can be adjusted so that the flight time is equal to the first bunch. It has been checked by beam simulations for a linear decay of the accelerating field strength from 125 to $98 \mathrm{MV} / \mathrm{m}$ and for a linear phase advance from 20_ to 32_ between the first and last bunch that the flight time from the photocathode to the gun exit is stabilised to within \pm 1 ps and the energy droop is reduced to $16.2>\gamma>13.9$ The linear phase advance is obtained by a frequency offset of the gun by $\Delta \mathrm{f}=+1.95 \mathrm{MHz}$. The repetition rate of the laser pulse train stays constant at $\mathrm{f}=2998.55 \mathrm{MHz}$, and the gun is tuned to a higher frequency $\mathrm{f}+\Delta \mathrm{f}=3000.5$ $\mathrm{MHz}$ by the movable tuners. The modified rf pilot frequency $\mathrm{f}+\Delta \mathrm{f}$ is synthesized by the synchronisation and timing system and fed to the rf power klystron through the preamplifier chain.

\section{CONCLUSIONS}

The $2 \frac{1}{2}$ cell gun with a conical backplane around the $\mathrm{Cs}_{2} \mathrm{Te}$ photocathode will be able to produce a pulse train of 48 ultrashort bunches with an electric charge of $21 \mathrm{nC}$ per bunch and a bunch length shorter than $2 \mathrm{~mm}$ fwhm from a laser pulse of $8 \mathrm{ps}$ fwhm duration. With a shorter laser pulse the bunch length becomes still shorter and no bunch compression is 
required any longer for $30 \mathrm{GHz}$ power production by the drive beam. Beam loading is most harmful at low beam energy. The increase of the flight time along the bunch train can be corrected by slightly shifting the gun frequency. Improved beam loading compensation schemes are required to avoid an unacceptable frequency shift of the drive beam for $30 \mathrm{GHz}$ power production. One method under investigation is to increase the stored energy in the first half cell using a higher mode resonance in a larger cell. A beam momentum higher than 5 to $7 \mathrm{MeV} / \mathrm{c}$ at the exit of the gun would also help to stabilize the flight time in the drift space between the gun and the subsequent accelerating section.

\section{REFERENCES}

[1] K. Batchelor, H. Kirk, J. Sheehan and M. Woodle, Proc. 1988 European Particle Accelerator Conf., Rome, p.954.

[2] R. Bossart, J.C. Godot, S. Lütgert, A. Riche, Nucl. Instr. and Meth. A 340 (1994), p.157.

[3] M. Bartsch, M. Dehler, X. Du, M. Dohlus, F. Ebeling, T. Weiland, Proc. Int. Conf. on Electromagnetic Field Problems and Applications, ICEF92, Hangzon, China, October 1992, p.405. 


\section{TABLE 1}

Computed rf parameters of $3 \mathrm{GHz}$ full cell versus iris diameter $\mathrm{d}$ for the monopole mode TM 010. Cell length $\mathrm{L}=50 \mathrm{~mm}$.

\begin{tabular}{c|c|c|c|c}
$\begin{array}{c}\text { Iris } \varnothing \\
\mathrm{d}[\mathrm{mm}]\end{array}$ & $\mathrm{Q}_{0}$ & $\begin{array}{c}\mathrm{R}_{\mathrm{eff}}^{\prime} \\
{[\mathrm{M} \Omega / \mathrm{m}]}\end{array}$ & $\begin{array}{c}\mathrm{k}_{12} \\
{\left[10^{-3}\right]}\end{array}$ & $\mathrm{E}_{\mathrm{pk}} / \mathrm{E}_{\mathrm{z}}$ \\
\hline 30 & 15400 & 17.9 & 4.33 & 1.11 \\
40 & 16100 & 14.1 & 15.6 & 1.10
\end{tabular}

TABLE 2

Beam characteristics calculated by MAFIA for a single bunch of $21 \mathrm{nC}$ charge. Field strength $E=100 \mathrm{MV} / \mathrm{m}$, laser phase $\varphi=30$, laser spot radius $r=6 \mathrm{~mm}$, laser pulse duration $\tau=8$ ps fwhm. Magnetic field strength of solenoid is $0.343 \mathrm{~T}$.

\begin{tabular}{lcc} 
Bunch Characteristics & Gun Exit & Solenoid Exit \\
\hline Emittance $, \varepsilon_{\mathrm{rn}}, \mathrm{mm}$ mrad & 61.8 & 86.9 \\
Beam energy, $\gamma$ & 13.9 & 13.9 \\
Energy spread, $(\Delta \gamma / \gamma), \%$ & 1.16 & 1.16 \\
Bunch length, $\sigma_{\mathrm{z}}, \mathrm{mm}$ & 1.08 & 1.10 \\
Bunch radius, $\sigma_{\mathrm{r}}, \mathrm{mm}$ & 5.7 & 7.6 \\
Buch radius, $\mathrm{r}_{\mathrm{max}}, \mathrm{mm}$ & 8.1 & 10.7 \\
Divergence, $\alpha_{\mathrm{rms}}, \mathrm{mrad}$ & 15.2 & 7.3
\end{tabular}

